\title{
Examination on Mechanical Behavior and Drilling Analysis of Fiber Metal Laminates
}

\author{
Nishant Singh Jamwal, Pritam Paul, Winowlin Jappes J T, Anushraj B, Brintha N C
}

\begin{abstract}
Fiber Metal Laminates (FML) are a class of composites that are recently employed to substitute sole metals in various applications like aerospace applications. In this investigation, a new type of FML was successfully fabricated using compression moulding in which Aluminium and ceramics mat are stacked in the presence of epoxy resin. To improve the bonding by ensuring the flow of resin through the laminates, drilling with various pattern on the Aluminium sheet and ceramic mat were performed before subjected to compression to form FML. Aluminium sheets with Zig-zag pattern performed in a better way due to the improvements in bonding. In addition, drilling operation was done on the FML to ensure the de-lamination resistance and machinability. The drill bit before and after drilling was inspected by using optical microscope to understand the machinability behaviour of the FML.
\end{abstract}

Keywords : Aluminium, Fiber, Moulding, Drilling.

\section{INTRODUCTION} produced by stacking interchanging layers of metals and fibers with epoxy as resin reinforcement. These materials have combined properties of metallic materials and fiber reinforced polymers. Aluminium is the general metal which is used in FML and Kevlar or Glass fiber can be used as fiber. The class of FML which uses Kevlar is known as ARALL (Aramid Reinforced Aluminum Laminates), the class of FML with glass fiber is known as GLARE (Glass Reinforced Aluminum), then there is CentrAl which surrounds a GLARE core with thicker layers of aluminium and there is a class of FML known as CARALL (CArbon Reinforced Aluminum Laminate) which is centred on carbon fibers.

The generation one of FML was presented with by combining the aramid and aluminium laminates in 1980 by Delft University, The Netherland. It was named as "ARALL" and was made to improve aerospace wings application. The

second generation of FML was later made in 1987 with glass fiber reinforcement and was envisioned for fuselage uses [1].

Revised Manuscript Received on December 5, 2019

* Correspondence Author

Nishant Singh Jamwal, Centre for Composite Materials, Department of Mechanical Engineering, Kalasalingam Academy of Research \& Education, Virudhunagar, Tamilnadu, India Email: jamwalnishant11@gmail.com

Pritam Paul, Centre for Composite Materials, Department of Mechanical Engineering, Kalasalingam Academy of Research \& Education, Virudhunagar, Tamilnadu, India Email: pablopaul1999@gmail.com

Winowlin Jappes J T*, Centre for Composite Materials, Department of Mechanical Engineering, Kalasalingam Academy of Research \& Education, Virudhunagar, Tamilnadu, India Email: winowlin@klu.ac.in

Anushraj B, Centre for Surface Engineering, Department of Mechanical Engineering, Kalasalingam Academy of Research \& Education, Virudhunagar, Tamilnadu, India Email: anushrajb@gmail.com

Brintha N C, Department of Computer Science and Engineering, Kalasalingam Academy of Research and Education, Virudhunagar, Tamilnadu, India. Email: brinthachris2k@gmail.com
$F_{\text {iber Metal Laminates (FML) is composites that are }}$

The glass fibers were later switched with carbon fibers to make up the deficits with glass fiber for aeronautics application and launching vehicles [2]. Fiber Metal laminates has a greater damage taking capability with outstanding properties when compared to simple composites and sole metals. Fiber Metal laminates also have an inherent high burn-through resistance with good damping and insulation properties. When the aluminium layers number is increased in FML, it leads to higher impact, tensile, and bending strength.

A patent in 1987 was filed by AKZO (AkzoNobel, Amsterdam, The Netherlands) on GLARE. A partnership between AKZO and ALCOA produced and commercialized this new composite [3].

Drilling is one of the best methods to make holes on materials. There are many machining parameters to yield holes without defects on materials. In this, the drill bit material, drilling process, drill bit geometry and machining parameters are few factors which helps in the determination of the quality of holes in the Fiber Metal laminates. The quality then can be enhanced by choosing appropriate cutting parameters like, tool wear, burr formation, surface finish, torque, hole diameter and circularity. The drill bit geometry is important in determining the machining quality of FML. For the quality of Drill bit geometry, Twist drill bit, brad point drill bit, slot drill bit, straight-flute drill bit, core drill bit, and step drill bit are carefully chosen by machining researchers community and for checking the machining parameters for the drilling quality, cutting speed, feed rate, spindle speed, and diameter of the hole are considered by numerous scholars.

Durao et al. [4] argued that delamination is the major and undesirable defect which is stated while drilling of hybrid structures. Numerous peel-ups or push downs fibers at drilled holes outline were stated in the defect zones as delamination [5]. The delamination and inter-ply errors arose by improper progression of the drill bit inside the material and occasionally due to numerous machining parameters such as high feed and the rate of speed. Peel-up and pushout defects were made by the drill bit geometry (Brad and Dagger drills) and machining parameters higher velocity and higher feed rate, which are found at the entry and exit of drill hole of the composites and witnessed around the perimeter of the holes that are drilled [6]. These defects occur in FML due to the depression at the entry of the drill bit and protrusion at the exit of the first and last laminate respectively, and also fiber unravelling and fiber coming off were seeming on each of the side, at the entrance and the exit [7].

The quality of the hole in the drilling operation is mainly controlled by the machining parameters.

Based on the preparation of the FMLs and the various 
observations taken, this paper deals with the investigation of the drilling on FML by checking the drill bit wear and the changes occurred in the diameter of the hole due the wear of the drill bit.

\section{EXPERIMENTAL PROCEDURE}

\section{A. Materials and Procedure}

The materials used for producing the Fiber Metal Laminates were, Aluminum sheet Al 2000 series with a thickness of $0.1 \mathrm{~mm}$ and $300 \times 150 \mathrm{~mm}$ dimensions, zirconium ceramic fiber mats of $300 \times 150 \times 25 \mathrm{~mm}$ dimensions with a density of $96 \mathrm{~kg} / \mathrm{m}^{3}$ and $0.10 \mathrm{MPa}$ tensile strength and LY556 grade epoxy resin.

\section{B. Preparation of FML samples}

For the preparation of first sample, first two sheets of aluminum of dimension $300 \times 150 \times 1 \mathrm{~mm}$ were cut, then a sheet of cemaric fiber mat of dimension $300 \times 150 \times 25 \mathrm{~mm}$ was cut. Then, the mould was taken, and wax was applied on the mould to avoid sticking of the sample on the mould during the process and it also helped in the easy removal of sample after the completion of the work. The epoxy resin and hardener with a ratio of $1: 2$ of $150 \mathrm{gms}$ were mixed. The stacking of layers in the order of aluminum-ceramic mat-aluminum was done by employing hand layup method. The resin was applied with each subsequent layer while stacking. Then the mould was mounted on the compression moulding machine and a curing time of $12 \mathrm{hrs}$ was given for the FML sample to be taken out.

The preparation of the second sample was like that of the first sample, just the stacked layers had a different sequence. The sequence of the second sample was ceramic mat-aluminum-ceramic mat. The rest of the procedure was same.

\section{Tensile Test}

The samples for the tensile test were made in accordance to ASTM D 638 with the dimensions $165 \times 13 \times 3 \mathrm{~mm}$. Both samples were prepared and were tested and an average of the three readings was taken.

\section{Impact Test}

The samples for the impact test were made in accordance to ASTM D 256 for Izod v-notch with the dimensions $60 \times 13$ $\mathrm{x} 3 \mathrm{~mm}$. Both the samples were prepared respectively and test was done and an average of the three readings was taken.

\section{E. Drilling Operations}

For the drilling operation on the samples, a $2 \mathrm{~mm}$ drill bit was taken. The holes were drilled using a centre tap drill machine. A total of 80 holes 20 in each row in a single sample were drilled. Different drill bits were used for the two samples. The distance of each hole in row was kept as $1 \mathrm{~cm}$.

\section{F. Drill bit Wear}

The wear on the drill bits were analysed using an optical microscope. The drill bits were first viewed under and optical microscope and the geometry of the drill bits were seen and pictures were taken. Then 20 holes were drilled in a row from the drill bit and again the drill bit was viewed under the optical microscope to check for any wear on the drill bit.
Again, 20 holes were drilled and the drill bit was analysed under an optical microscope for the tool wear. This procedure was continued and 80 holes were made on the sample.

Then, for the second sample another drill bit was taken and the same procedure was followed for checking the drill bit wear from the machining process.

\section{G. Analysing the drilled holes}

The drilled holes were analysed under the optical microscope for the effects of tool wear on the diameter of the holes. Factors like diameter of the holes and fibre delamination were checked under the optical microscope. The pictures of the holes were taken using optical microscope and profile projector and a comparison between the first hole and the last hole was made which is presented in the results section of this paper.

\section{RESULT AND DISCUSSION}

\section{A. Tensile Test}

The table 1 shows the tensile strength of the two samples obtained from the tensile test. It can be inferred that the tensile strength of the sample with the stacking order (MAM) is slightly more than the sample with the stacking order (AMA). The difference in tensile strength is not much but due to the change in the stacking order this difference has occurred. The tensile strength of the MAM is more due to the random orientation of the fibres in a mat. Due to this random orientation the load during the tensile test was distributed among the multidirectional fiber arrangement. This is also shown in the Figure 1 and 2.

Table 1: Measured Tensile Strength of the samples

\begin{tabular}{|l|l|l|l|l|}
\hline \multirow{2}{*}{ Samples } & \multicolumn{4}{|c|}{ Tensile Strength (MPa) } \\
\cline { 2 - 5 } & Test 1 & Test 2 & Test 3 & Average \\
\hline $\begin{array}{l}\text { Mat Aluminum Mat } \\
\text { (MAM) }\end{array}$ & 55.97 & 54.98 & 55.21 & 55.39 \\
\hline $\begin{array}{l}\text { Aluminum Mat Aluminum } \\
\text { (AMA) }\end{array}$ & 53.65 & 54.02 & 56.56 & 54.74 \\
\hline $\begin{array}{l}\text { Mat aluminium mat with } \\
\text { pattern (MAM-P) }\end{array}$ & 58.654 & 59.120 & $\begin{array}{l}58.25 \\
4\end{array}$ & 58.68 \\
\hline $\begin{array}{l}\text { Aluminium mat aluminium } \\
\text { with pattern (AMA-P) }\end{array}$ & 56.685 & 56.410 & 57.02 & 56.71 \\
\hline
\end{tabular}

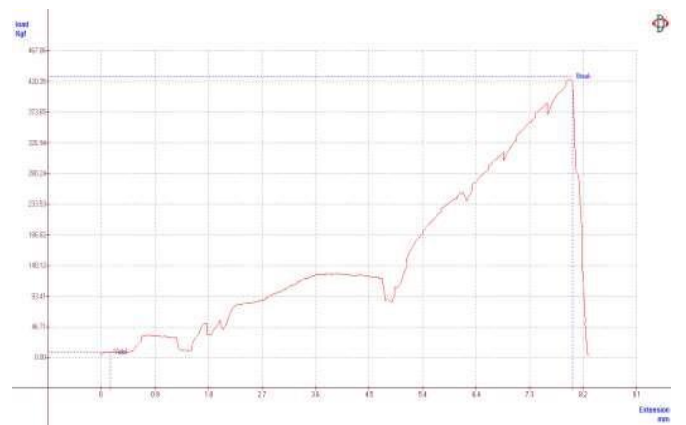

Fig 1: Graph 1 load- displacement curve for MAM 


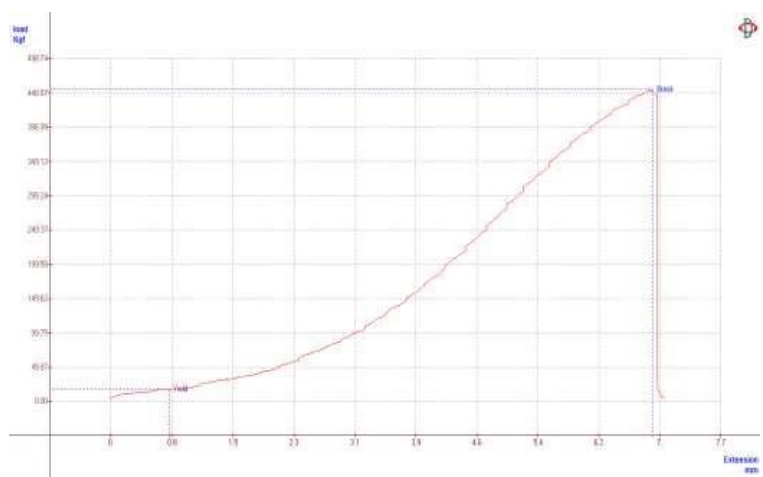

Fig 2: Graph 2 load- displacement curve for AMA

From the graph 1 and 2, it can be seen that the load-displacement curve for AMA is growing without any fluctuations, it is because the sample is aluminium dominant and thus the tensile loading is exponential on the sample. Whereas, in the MAM sample the curve has fluctuations, it is due to the breaking of fibers in the mat during the tensile loading.

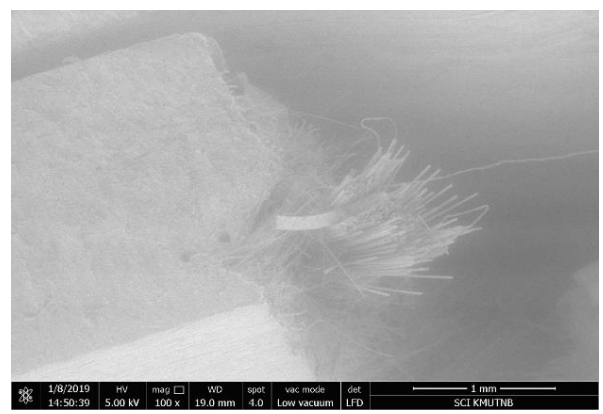

Figure 3: Images of samples after the tensile test using SEM for AMA.

Figure 4: Images of samples after the tensile test using SEM for MAM.

Figure 3 and 4 displays the images of the two samples taken using SEM after the tensile test. It can be seen in the sample with stacking order AMA that due to the presence of aluminium on the outer surfaces, the inner layer fibers of the mat were pulled out during the testing. In the second sample (MAM) the outer surfaces had mats where the fibers were being pulled of outwards and thus the strength was slightly higher. In this case, laminated composites with zig-zag pattern performed better in both cases. This could be due to the enhancement in the effect of interlocking of resin with fiber and aluminium

\section{B. Impact Test}

The table 2 shows the Impact strength of the samples. Here, the sample with the stacking order as MAM has higher impact strength than the MAM sample. This was due to the presence of ceramic mat at the outer layer of the sample. The

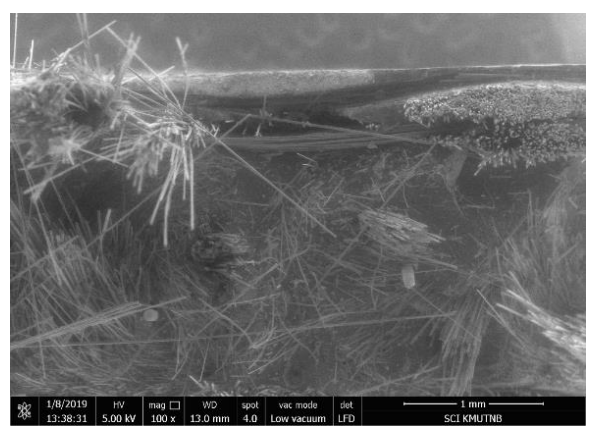

mat in the outer layer has more impact absorption capacity, thus the impact strength is more for this sample. Whereas, in the AMA sample the outer layer is aluminum, the penetration was easy and the impact strength reduced.

Table 2: Measured Impact strength of the samples.

\begin{tabular}{|l|l|l|l|l|}
\hline Samples & \multicolumn{4}{|l|}{ Impact strength (MPa) } \\
\hline & Test 1 & Test 2 & Test 3 & Average \\
\hline $\begin{array}{l}\text { Mat aluminium mat } \\
\text { (MAM) }\end{array}$ & 6.658 & 6.546 & 6.513 & 6.572 \\
\hline $\begin{array}{l}\text { Aluminium mat aluminium } \\
\text { (AMA) }\end{array}$ & 1.598 & 1.673 & 1.687 & 1.652 \\
\hline $\begin{array}{l}\text { Mat aluminium mat with } \\
\text { pattern (MAM-P) }\end{array}$ & 7.856 & 8.153 & 7.546 & 7.852 \\
\hline $\begin{array}{l}\text { Aluminium mat aluminium } \\
\text { with pattern (AMA-P) }\end{array}$ & 3.123 & 2.965 & 3.546 & 3.211 \\
\hline
\end{tabular}

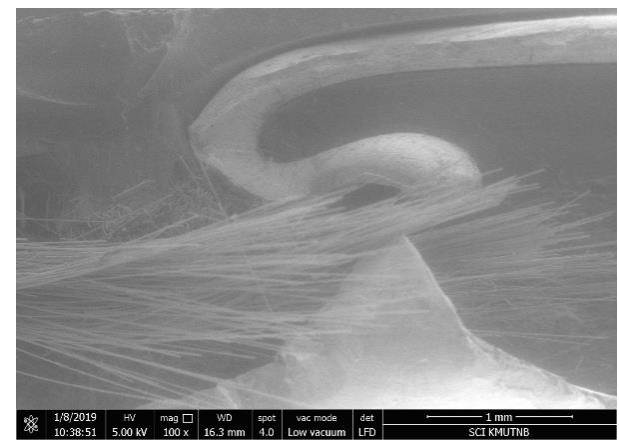

Figure 5: SEM images of samples after Impact test of AMA

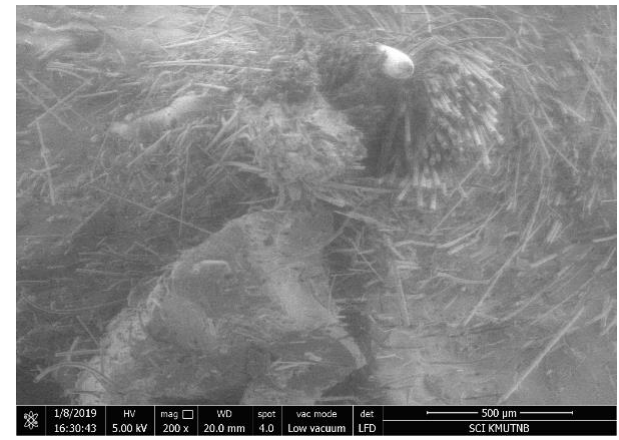

Figure 6: SEM images of samples after Impact test of MAM

Figure 5 and 6 displays the images of the sample after the impact test taken using SEM. It can be seen in the pictures that in the AMA sample due to the impact testing there was plastic deformation in the aluminum sheet and due to this the impact strength decreased. Whereas, in the MAM sample, the impact was absorbed by the ceramic mat and thus the impact strength was more. Similar to tensile performance, laminates with pattern performed better in this case also.

\section{Drilling studies}

The drilling operation was performed on the two samples AMA and MAM as discussed previously.

Figure 7 shows the images of the drill bit taken using an 


\section{Examination on Mechanical Behavior and Drilling Analysis of Fiber Metal Laminates}

optical microscope before the drilling operation. In these images (a) and (b) we can see the geometry of the drill bit and the drill bit nose is sharp.
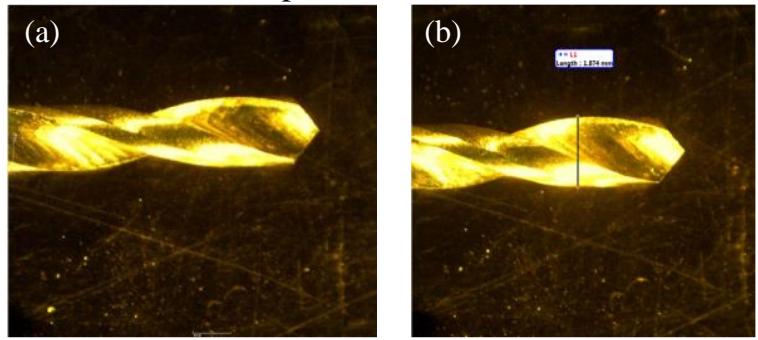

Figure 7: optical microscope images of drill bits before the drilling operation

Figure 8 shows the drill bit's geometry after the drilling holes in AMA sample. In this, (a) Shows the drill bit geometry after drilling first 20 holes and (b), (c) and (d) shows the drill bit geometry of the drill after every 20 holes respectively. It can be seen from the images that, with the time drill bit wear occurred and we can see that after the drilling operation was completed the nose of the drill bit had become almost blunt from the wear.
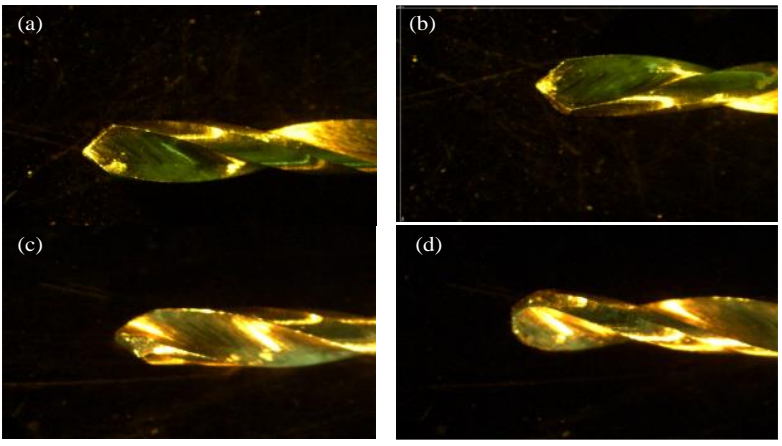

Figure 8: Drill bit images after the drilling of AMA sample

Figure 9 shows the drill bit geometry after drilling of MAM sample. In this, (a), (b), (c) and (d) shows the images of drill bit geometry after every 20 holes. Here also, the wear has occurred on the drill bit after drilling. The amount of wear is lesser than that of AMA sample as in AMA sample aluminum is present in the outer surfaces. Whereas, drilling ceramic mat is comparatively easy.
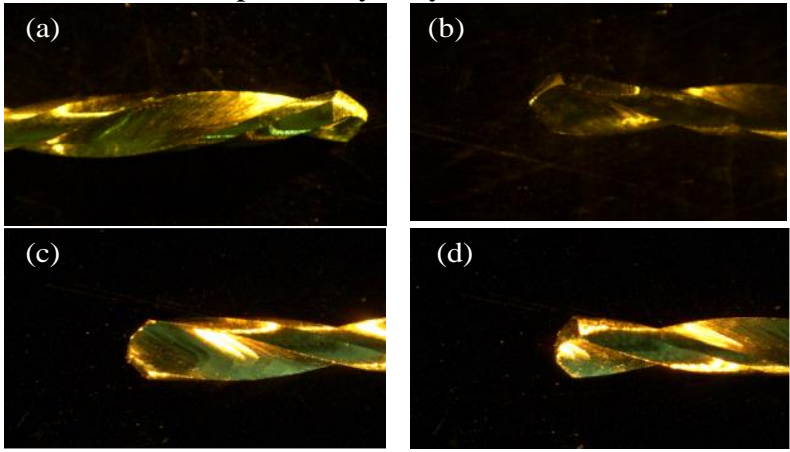

Figure 9: Drill bit images after the drilling of MAM sample

Figures 10 and 11 shows the first and last holes of the AMA and MAM samples using Optical microscope. It can be seen from the images that with the tool wear the geometry of the holes has changed. There is more de-lamination in the MAM sample than that of AMA sample due to the presence of the fibrous ceramic mat. During the drilling process the fibres from the ceramic mat were pulled out. With the wear in the tool more de-lamination occurred.
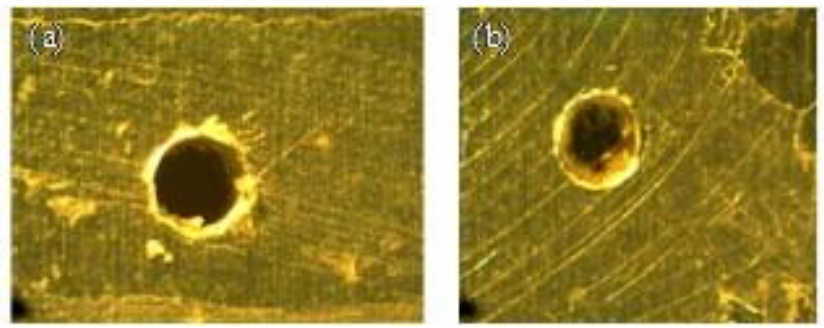

Figure 10: First and last holes of the AMA
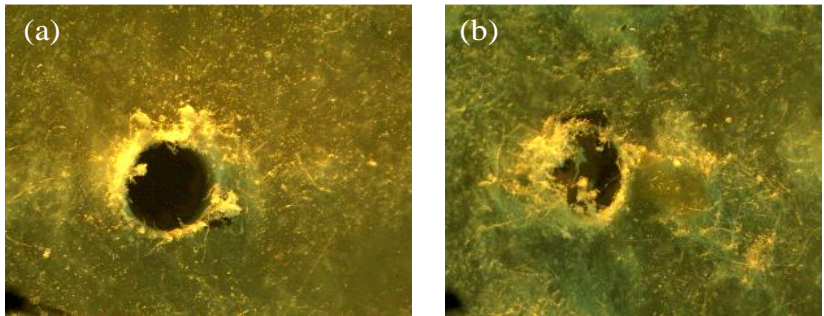

Figure 11: First and last holes of the MAM

\section{CONCLUSION}

FML with pattern performed in a better way both tensile and impact testing conditions. And the presence of ceamic at top and bottom behaved successfully on tensile and impact condition. This could be due to the random oriented fibers placed in the mat may be transferred the loads effectively. The tool wear is found to be more while drilling AMA sample due to the aluminum layer present in the outer layer. And the tool wear affects the geometry of the drilled holes. The presence of fiber negatively responding on tool wear.

\section{REFERENCES}

1. Vlot A, Vogelesang LB and De Vries TJ. Towards application of fibre metal laminates in large aircraft. Aircraft Eng Aerosp Tech 1999; 71: $558-570$.

2. Vogelesang LB and Vlot A. Development of fibre metal laminates for advanced aerospace structures. J Mater Process Technol 2000; 103: 3-7.

3. Vlot, A. and Gunnink, J. W. Fibre metal laminates, 2001 (Kluwer Academic Publishers, Dordrecht, The Netherlands).

4. Dur ao LMP, Gonc, alves DJS, Tavares JMRS, Albuquerque VHCD, Vieira AA and Marques AT. Drilling tool geometry evaluation for reinforced composite laminates. Compos Struct 2010; 92: 1545-1550.

5. Faraz A, Biermann D and Weinert K. Cutting edge rounding: an innovative tool wear criterion in drilling CFRP composite laminates. Int J Mach Tools Manuf 2009; 49: 1185-1196.

6. Davim JP and Reis P. Drilling carbon fiber reinforced plastics manufactured by autoclave-experimental and statistical study. Mater Design 2003; 24: 315-324.

7. Ashrafi SA, Sharif S, Farid AA and Yahya MY. Performance evaluation of carbide tools in drilling CFRP-Al stacks. J Compos Mater 2013; 48: 2071-2084.

8. Frizzell RM, Mccarthy CT and Mccarthy MA. Predicting the effects of geometry on the behaviour of fibre metal laminate joints. Compos Struct 2011; 93: 1877-1889.

9. Botelho, E. C., Silva, R. A., Pardini, L. C., and Rezende, M. C. A review on the development and properties of continuous fiber/epoxy/aluminum hybrid composites for aircraft structures. Mater. Res., 2006, 9(3), 247256.

10. $\mathrm{Xu} \mathrm{S}$ and Chen PH. An historic overview of the development of fibre metal laminates. Procedia Eng 2013; 67: 489-496.

\section{AUTHORS PROFILE}




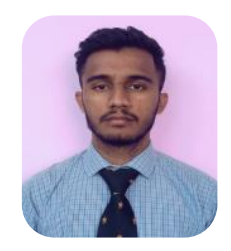

Mr. Nishant Singh Jamwal has completed his Bachelor's of Technology in Mechanical Engineering from Kalasalingam Academy of Research and Education, Tamil Nadu. His area of expertise is Automotives and he is actively working in material science. He has done projects in Fibre Metal Laminates and composites and has attended National and International conferences in the aforementioned fields.

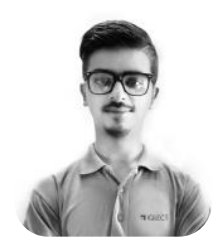

Mr. Pritam Paul has obtained his Bachelors of Technology in Mechanical Engineering from Kasalalingam Academy of Research and Education, Tamil Nadu, India in 2019. His area of expertise is Automobile, although he is equally interested in the field of Advance Jet Propulsion systems and Composites with main focus on Fibre Metal Laminates and the mechanical behavior along with the drilling studies on them. He has attended National and International conferences in the aforementioned fields.

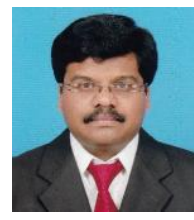

Dr. Winowlin Jappes J T graduated in 1997 from Manonmaniam Sunderanar University, India in Mechanical Engineering. In 1999, he has completed his masters in Production Engineering from Annamalai University. He completed his Ph.D degree in 2004 in the area of Composite Deposition at Indian Institute of Technology Madras, Chennai. He has completed three DST funded research projects and published more than 125 research articles which include 65 International Journal papers. Currently, he is working as Senior Professor in Kalasalingam University, India. His research interest includes high performance composite materials, machining of hard materials, optimization techniques, etc. At present, he is working as Professor and Dean, School of Automotive and Mechanical Engineering, Kalasalingam Academy of Research and Education, India.

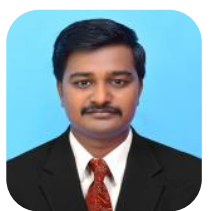

Mr. Anushraj B graduated in 2012 from St.Xavier's Catholic College of Engineering, India. In 2014, he received his M.E Degree in Energy Engineering from Regional Campus of Anna University, Tirunelveli, India. Currently, he is a research scholar at Kalasalingam Academy of Research and Education, India.

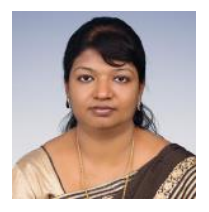

Dr. Brintha N C graduated in 2002 from Manonmaniam Sunderanar University, India. In 2006, she received her M.E Degree with distinction in Computer Science and Engineering from A.K.C.E, Anna University, Chennai. She completed her P.hd degree in 2018 in the area of Cloud Manufacturing under Anna University, Chennai. Currently, she is working as Associate professor/ CSE in Kalasalingam Academy of Research and Education, India. Her research interests include Cloud computing, Optimization, Scheduling, Cloud Manufacturing and so forth. 